\title{
The effect of motivation of success of university students on personal-professional competence: Mediation role of lifelong learning tendency
}

\author{
Halil Ekşi ${ }^{1}$, Mustafa Özgenel ${ }^{2}$, Esin Metlilo $^{3}$ \\ ${ }^{1}$ Deparment of Education Sciences, Marmara University, Turkey \\ ${ }^{2}$ Department of Primary Education, Istanbul Sabahattin Zaim University, Turkey \\ ${ }^{3} \mathrm{PhD}$ Student in Education Administration, Istanbul Sabahattin Zaim University, Turkey
}

\begin{tabular}{|c|c|}
\hline Article Info & ABSTRACT \\
\hline Article history: & \multirow{10}{*}{$\begin{array}{l}\text { In this study, the relationship between motivations for success, personal- } \\
\text { professional competencies and lifelong learning tendencies of university } \\
\text { students were investigated. The study group consists of } 344 \text { University } \\
\text { students from Turkey and Kosovo. In this research, the collection of data was } \\
\text { done by "Personal-Professional Competencies Perception Scale, "Success } \\
\text { Oriented Motivation Scale" and "Lifelong Learning Tendency Scale". } \\
\text { In order to determine the relationship between variables in the analysis of the } \\
\text { data, correlation analysis was performed and tested with the structural } \\
\text { equation model. According to the results of the research; there was a positive } \\
\text { significant correlation between motivation for success and personal } \\
\text { professional competence, and a positive significant relationship between } \\
\text { lifelong learning and personal-professional competence. Motivation for } \\
\text { success positively affects personal-professional competencies and lifelong } \\
\text { learning tendencies. It has been determined that lifelong learning tendency is } \\
\text { a partial tool in this relationship. }\end{array}$} \\
\hline Received Apr 12, 2020 & \\
\hline Revised Jul 22, 2020 & \\
\hline Accepted Aug 5, 2020 & \\
\hline & \\
\hline Keywords: & \\
\hline Lifelong learning & \\
\hline Motivation for success & \\
\hline $\begin{array}{l}\text { Personal-professional } \\
\text { competence }\end{array}$ & \\
\hline University student & \\
\hline
\end{tabular}

This is an open access article under the CC BY-SA license.

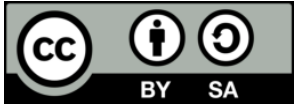

\section{Corresponding Author:}

Esin Metlilo,

$\mathrm{PhD}$ Student in Education Administration,

Istanbul Sabahattin Zaim University,

Halkalı Cad., No: 281, 34303 Küçükçekmece/İstanbul, Turkey.

Email: metliloesin@gmail.com

\section{INTRODUCTION}

The concept of competence in European Higher Education Area is seen as to fulfil the features needed in professional and personal development, and the ability to use them [1]. Bandura [2], defined competence as a capacity that includes the cognitive, emotional, behavioural and social skills of the person and consists of being obliged to be guided and organized in many purposes. Swanson and Holdton [3] describe competence as characteristic features such as knowledge, ability, skill and attitude related to the individual's position. Similarly, competence can be defined as personal-professional skills and behaviours of the organization in order to achieve its goals and to fulfil the roles of the employees [4]. According to Westera [5], the evaluation of competence as a satisfactory activity has a significant effect on the environment. Research on competences was first conducted in 1950 [6]. In 1973, it gained speed with McClelland; and classified as motives and personal competences [7]. When the competence is examined from the personal and professional dimension, it is correct to express the competence as the basic characteristics of the individual showing effective or superior performance results in a job [8]. 
Personal-professional competencies can also be described in terms of observable behaviours that include discriminating knowledge, attitudes and skills in creating excellent performance [9]. In independent studies for university students including personal and professional competencies, is aimed to gain qualifications related to taking responsibility, learning, communication and social field [10]. Personalprofessional competence increases the motivational aspect of an individual by revealing the cognitive ability and necessary effort for the successful performance of an individual [11] and thus shows its impact on success [12]. Personal and professional competencies are said to act together with multiple factors. In this context, lifelong learning has also taken part in the mobility.

The concept of lifelong learning was first used at the beginning of the XX century and it was argued that the limitation of education in terms of place and time was wrong. Lifelong learning was mentioned by Dewey, Lindeman and Yeaxle in the 1920s and it was stated that it was possible to carry out education from cradle to grave. In addition, Lindeman tried to explain the importance of lifelong learning in his work "The Meaning of Public Education" with the words "Education is Life" [13]. With the emphasis on the universal dimension of education reform, 1996 was declared as the year of lifelong learning [14, 15]. At the meeting held in Lisbon in 2000 by members of the Council of Europe, a 10-year strategy was signed by state leaders and lifelong learning was considered the most important element. "The Lifelong Learning Memorandum" adopted by the Council of Europe has greatly contributed to the development of the lifelong learning approach and its active role in all countries. "The Lifelong Learning Memorandum" which was implemented by the Council of Europe, emphasized that lifelong education and learning is not only compulsory for work life and acquisition of knowledge for education, but compulsory also for "professional and personal development", "social cohesion", "active citizenship" and "European citizenship" [16].

OECD [17] emphasizes that, the countries that want to place innovation at the centre of national and social-economic policies within the framework of lifelong learning, need to adopt a new culture for the society in order to gain individual innovative behaviours. To create such an innovative culture and to educate innovative individuals, entrepreneurship, innovation and creativity of individuals should be gained with the young age and teach the truth of the sustainability of education at all ages [18]. According to this approach, the age of the individual does not matter. Lifelong learning approach sees people as students at all ages [19]. Lifelong learning is valid and necessary for all. It is an opportunity for adults to complete their shortcomings, it also allows completion of parts of education in the daily life [20]. Lifelong learning also means providing a second learning opportunity for the development of basic skills [21]. Numerous definitions have been made on lifelong learning. MEB [22] defines lifelong learning as "all kinds of learning activities that the individual participates in order to develop his/her knowledge, skills and competences with an approach related to personal, social, social and employment". Lifelong learning is also described as, better featured labor force and as a democratic environment that includes society completely [23]. Lifelong learning encompasses both formal and non-formal education and enables the enrichment of life and learning in mutual interaction [24]. Although there are differences in the definitions made about lifelong learning according to their perspectives, it is seen that lifelong learning has vital importance in all definitions [25]. Lifelong learning is seen as an integral part of higher education within the scope of the Bologna Declaration [26]. In motivation, it is also an integral part of lifelong learning.

Motivation is an important factor that facilitates learning [27]. Motivation is the power that drives the individual towards a specific goal [28]. Thanks to this power, success is achieved. One of the important issues to be emphasized in education and training are motivation for success and its characteristics [29]. Just like motivation, motivation for success is a complex and multifaceted process [30]. Motivation for success helps the individual to use his time and energy to reach his or her goals [31]. Motivation of success is all the efforts that are made continuously to activate one or more people, towards a certain success (in one direction and one goal) [32]. Motivation for success is closely related to the integrity of learning and the resulting quality of learning [33]. Motivation for success can also be considered as a phenomenon that directs the individual to success or failure [34]. The learning of the student with high motivation for success is seen at high levels [35]. Students with high motivation for success are generally successful students [36]. According to McClleland [37], motivation for success is expressed as individuals who give importance to development, who are willing to take risks, which seem to be committed to their jobs and who endure difficulties and achieve success. It is emphasized that there is a difference between individuals with this feature, from individual to individual, from society to society. Motivation has no way of achieving success, which is shaped by the behaviour of the environment, social values and the individual and leads to goals [38]. Motivation has no relation of achieving success; it is shaped by the behaviour of the environment, social values and the individual and leads to goals [38]. Motivation for success is classified as a theory that determines three different needs as a need for success, membership need and need for power [39]. Motivation for success is a very strong predictor of perceived success and academic skill [40]. 
When the related literature is examined, it is seen that there are many researches on the subject. Some of these researches were examined whether there is a relationship between different variables related to lifelong learning, some of them are personal-professional competencies and some of them are related to motivation of success and they are subjected to analysis of these variables. In research on lifelong learning; students' lifelong learning tendencies and professional self-efficacy perceptions and professional concerns [41-43], the relationship between lifelong learning competence and self-efficacy expectation and personality [44], the effect of undergraduate education on lifelong learning [45], the comparison of lifelong learning with internet usage time and the main discipline [46], analysis of lifelong learning in terms of gender variable [47] and the level of lifelong learning and personal-professional competencies [48] were investigated. In researches related to motivation for success, the relationship between success-oriented motivations and independent variables (gender, class, department, academic average, university preference rankings) [34], dimension of the relationship between motivation of success and philosophies of education [49], effects of success motivation on professional performance [50] have found.

Although there are numerous studies about these three variables which are the subject of educational research, there are no studies that identify three variables at the same time and deal with them through a model. The effect of success motivation on personal-professional competence and the mediating role of lifelong learning in this impact process is thought to be an important element in the occupations and tasks that university students will perform in later life. From this point of view, the aim of the study is to reveal the relationship between university students' motivations for success, personal-professional competencies and lifelong learning and to explain this relationship through lifelong learning.

\section{RESEARCH METHOD}

Relational survey model was employed to determine the relationship between motivation for success, personal-professional competencies and lifelong learning tendencies of university students. The relational survey model is a research model that is conducted to determine the relationships and connections between two or more variables [51].

In the study, a model was tried to be tested to explain the role of mediation in the relationship between motivation for success and personal-professional competence of lifelong learning tendency of university students. According to the model; motivation of success affects both self-occupational competence (dependent variable) as an independent variable directly and lifelong learning (mediating variable) through indirectly. The independent variable - motivation for success together with tool variable - lifelong Learning affects the personal-professional competence (dependent variable). The test of the model was carried out with the structural equation model. Structural equation modelling is more powerful than other multiple analysis techniques in order to provide separate and complex relationships between a group of variables [52]. Structural equation modelling is a multivariate method that defines the causality and relationship between observable and hidden variables as a model based on a specific theory [53]. The structural equality model is a statistical method used by educational scientists and sociologists and has recently been used by economists and biologists. The structural equation model also provides researchers with a comprehensive method for testing theories. Considering the measurement errors found in most disciplines has also increased its importance one more time [54].

\subsection{Universe and sample}

The population of the study consists of university students studying in Istanbul Sabahattin Zaim University Faculty of Education, Krrklareli University Faculty of Science and Letters, and Faculty of Education of Ukshin Hoti University in Prizren, Kosovo in 2018/2019 academic year. In determining the sample size, Structural Equation Model features were taken into consideration. According to Eroğlu [55], the Structural Equation Model has a sample size determined by some researchers to be between 200-500; Weston and Gore [56] suggest that the sample size should be more than 200 people. Accordingly, the study sample consists of 400 (Istanbul-100, Kirklareli-200 and Prizren-100) university students provided that they are in different countries. During the analysis, the number of samples applied to the scale and analyzed was reduced to 344 students and analyzes were made on this issue. The sample of the study was determined randomly by simple random sampling method. University students involved in testing the study model, $87.2 \%(\mathrm{n}=300)$ were female and $12.8 \%(\mathrm{n}=44)$ were male students. It was determined that, $7.6 \%(\mathrm{n}=26)$ were classroom teachers, $18.0 \%(\mathrm{n}=62)$ were preschool teachers, $5.2 \%(\mathrm{n}=18)$ were computercommunication and $69.2 \%(\mathrm{n}=238)$ were from other departments. 


\subsection{Data collection tools}

Three scales were used as data collection tools to investigate whether lifelong learning tendency plays a role in the achievement motivation and personal-professional competence levels of university students participating in the research.

a. Personal-professional competencies perception scale: The five-point Likert-type "Personal-Professional Competencies Perception Scale was developed by Kazu and Demiralp [10] in order to determine the personal-professional competences of undergraduate students studying at the university. The scale consists of four sub-dimensions and 18 items. The sub-dimensions were listed as "Ability to work independently and take responsibility (I can use my strengths in my work)", "Field-specific competence (I analyze problems related to my field)", "Learning competence (Solutions to problems that prevent me from learning I produce)" and "Communication and social competence (I try to get to know different cultures)”. The Cronbach's alpha coefficient in this study was 0.91 .

b. Lifelong learning tendency scale: Five-point Likert-type "Lifelong Learning Tendency Scale was used by Gür and Arsal [57] to determine the lifelong learning tendencies of university students. The scale consists of two sub-dimensions and 17 items. The sub-dimensions were listed as willingness to learn (I prepare the necessary resources for learning in advance)" and openness to development (I give importance to progress in professional career)". The Cronbach's alpha coefficient in this study was 0.86 .

c. Success oriented motivation scale: Semerci [36] developed a five-point Likert-type "Success-Oriented Motivation Scale which is used as a data collection tool to determine the motivation of success of university students. The scale consists of four sub-dimensions and 35 items. The sub-dimensions were listed as "External effects (new information opens up my horizon)", "Internal effects (my desire to succeed increases as I succeed)", "Target enlargement (my desire to succeed increases while successful)" and "Self-awareness (I believe I will succeed no matter what)". The Cronbach's alpha coefficient in this study was 0.89 . During the data collection process, the students were informed about the scale and the subject of the study and the questionnaires were applied in the classroom.

\subsection{Data analysis}

The statistical analysis of the data obtained from the research was carried out by using SPSS and AMOS statistical programs on computer. In the analysis of the data, correlation analysis and structural equation model were used to determine the relationship between frequency, percentage calculations and variables, which are descriptive statistical methods. In addition, extreme values analysis, normality analysis, linearity analysis was conducted and multiple connection problems were investigated. In order to determine normality, skewness and kurtosis values were used. According to Hahs-Vaughn \& Lomax [58], the normal distribution of data is considered to be in the range of -2 to 2 of skewness and kurtosis.

In this study, the coefficients of skewness of the variables were determined as; motivation for success was -0.5 , personal-professional competence was -0.3 and lifelong learning was -0.11 in the willingness sub-dimension and -0.14 in the openness to lifelong learning sub-dimension. Kurtosis coefficients of variables were determined as; motivation for success was -0.9, personal-professional competence was -0.6 , lifelong learning was 0.1 in the willingness sub-dimension and 0.2 in the openness to lifelong learning sub-dimension. The linear distribution assumption of the data was determined on the scattering diagram. It is seen that the variables in the scattering matrix are scattered around the line and fulfil the linearity rule. Data analysis coefficients and shapes that conform to the normality and linearity assumptions have confirmed the ability to use the data in the specified analysis operations. Pearson Correlation Coefficient was calculated to determine the relationship between variables. Correlational research indicates the relationship between two or more variables [51] and the direction and degree of this relationship [59]. The correlation coefficient is between +1 and -1 . A correlation coefficient of +1 and -1 indicates a perfect relationship and a correlation coefficient of 0 indicates no correlation. The positive coefficient indicates that one of the variables increases while the other increases, while negative indicates that one of them increases and the other decreases. If the correlation coefficient is less than 0.30 , the relationship is low/weak, the relationship in the range of $0.30-0.70$ is medium and if the relationship is higher than 0.70 , indicates that the relationship is high/strong. Structural equation model was used to test the theoretical model [51]. Maximum likelihood (ML) method was used in the structural equation model. Maximum likelihood is that the observations are independent of each other and that the observed variables have a multivariate normal distribution [53]. There are two separate models to be followed in structural equation modelling. The first is the measurement required for a successful analysis and the second is the goodness of fit index values. The first rule of good research is to start with the measurement model. Compliance index 
values, on the other hand, ensure that each model is judged in integrity in the independent evaluation criteria, which is necessary for the latest evaluations of the model. Compliance indexes are shown in Table 1.

Table 1. Structural equation model fit index

\begin{tabular}{lcc}
\hline Compliance Test & Good fit & Adequate fit \\
\hline$x^{2} / d f$ & $0 \leq x^{2} / \mathrm{df}<3$ & $3<x^{2} / \mathrm{df} \leq 5$ \\
CFI & $0.95 \leq \mathrm{CFI} \leq 1.00$ & $0.90 \leq \mathrm{CFI}<0.95$ \\
RMSEA & $0 \leq \mathrm{RMSEA} \leq 0.05$ & $0.08 \leq \mathrm{RMSEA} \leq 0.05$ \\
TLI & $0.95 \leq \mathrm{TLI} \leq 1.00$ & $0.90 \leq \mathrm{TLI}<0.95$ \\
RMR & $0 \leq \mathrm{RMR} \leq .05$ & $05<\mathrm{RMR} \leq 0.80$ \\
NFI & $0.95 \leq \mathrm{NFI} \leq 1.00$ & $0.90 \leq \mathrm{NFI}<0.95$ \\
GFI & $0.95 \leq \mathrm{GFI} \leq 1.00$ & $0.90 \leq \mathrm{GFI}<0.95$ \\
AGFI & $0.90 \leq \mathrm{AGFI} \leq 1.00$ & $0.85 \leq \mathrm{AGFI}<0.95$ \\
\hline
\end{tabular}

Table 1 contains $x^{2}=$ Chi-squre $\mathrm{df}=$ Degree of Freedom GFI= Goodnes-of fit index); AGFI= Adjusted goodness-of-fit index CFI=Comparative fit index RMSEA = The root means square error); NFI=Normed fit index; TLI= Tucker Lewis Index) [53, 60-62]. In the structural equation model, the mediating roles of the variables can be analyzed by various methods. In this research, the model analysis given in Figure 1.

When the model was tested, it was analyzed according to the model order given in Figure 1. Effect of motivation of success on personal-professional competence (path a); The effect of achievement motivation on lifelong learning (path b) and the effect of lifelong learning on personal-professional competence (path c) were calculated. Finally, the effect of motivation for success and lifelong learning on personal-professional competence was tested. While the model was tested, the modification was made because the pathway to lifelong development and the coefficient of personal-professional competence were meaningless ( $p>.05)$. As a result of the analysis, the path coefficient (a) between the motivation of achievement and personal competence given in Figure 1 was examined and whether the mediation of lifelong learning mediated was evaluated according to the adaptation indices.

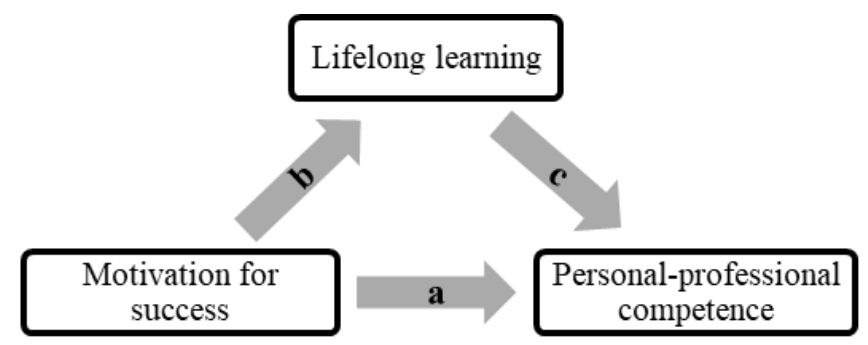

Figure 1. Model to be analyzed with structural equation model

\section{RESULTS AND DISCUSSION}

Pearson product correlation analysis was used to determine the relationships between achievement motivations, personal-professional competencies and lifelong learning tendencies of university students. The data obtained as a result of correlation is shown in Table 2.

Table 2. Pearson moments product correlation analysis findings of variables

\begin{tabular}{lcc} 
& Motivation for success & Personal-professional competence \\
\hline Motivation for success & 1 & \\
Personal-professional competence & $.587^{* *}$ & 1 \\
Willingness to Lifelong Learning & $.556^{* *}$ & $.465^{* *}$ \\
Personal-professional competence & $.360^{* *}$ & $.362^{* *}$ \\
${ }^{* * *} \mathrm{p}<.01 ; \mathrm{n}=344$ & &
\end{tabular}

As a result of the correlation analysis of the pearson product, the correlation between motivation for success, personal-professional competencies and lifelong learning of university students was determined as follows: there was a positive and medium relationship $(\mathrm{r}=.587 ; \mathrm{p}<0.01)$ between motivation of achievement and personal-professional competence; there was a positive and medium relationship $(\mathrm{r}=.556 ; \mathrm{p}<0.01)$ 
between of motivation for success and willingness for lifelong learning; there was a positive and significant relationship $(r=.360 ; \mathrm{p}<0.01)$ between motivation for success and openness to lifelong learning. On the other hand, there were positive and medium relationship $(r=.465 ; \mathrm{p}<0.01)$ between personal-professional competence and willingness to lifelong learning; and there was a positive and medium $(r=.362 ; \mathrm{p}<0.01)$ significant relationship between personal-professional competence and openness to lifelong learning.

According to Figure 2, structural equality model was used to test the theoretical model to determine the effects of motivation for success, lifelong learning and personal-professional competence. Path analyzes were conducted to determine the linearity of relationships between motivationfor success, personalprofessional competencies, and lifelong learning of university students and the role of lifelong learning in this relationship dimension. If there is a causal sequence of three (or more) variables, the mediator variable can be mentioned. There are certain rules that a variable must provide in order to be a mediator. Taking these rules into consideration, path analyzes were performed. The independent variable (motivation for success) should have an effect on the dependent variable (personal-professional competence).

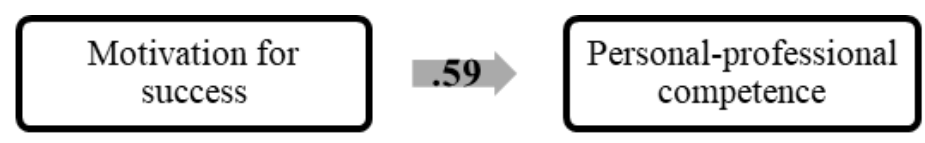

Figure 2. First model of path analysis

When the motivation of success and personal-professional competence model were tested, the relationship between them was found to be statistically significant. Motivation of success $\left(\mathrm{R}^{2}=.59 ; \mathrm{p}<.05\right)$ has a positive effect on personal-professional competence. The independent variable (motivation for success) should have an impact on the mediating variable (willingness to lifelong learning and openness to lifelong learning) as shown in Figure 3.

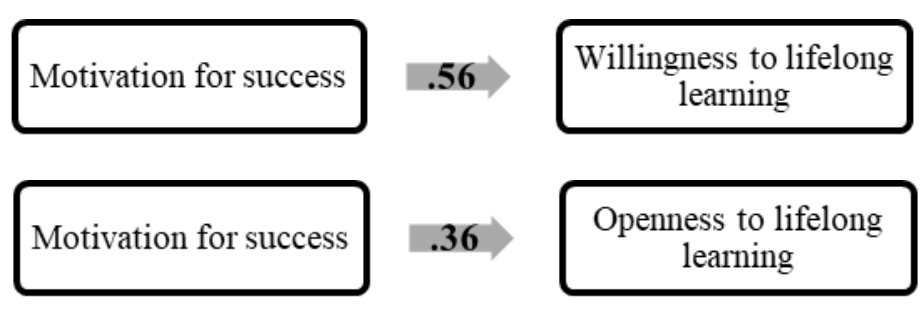

Figure 3. Second model of path analysis

When the model established with motivation for success, lifelong learning subscale and willingness and openness to development were tested, the relationship between them was found to be statistically significant. It was determined that motivation for success had a positive effect on the relationship between motivation for success, willingness to learn $\left(\mathrm{R}^{2}=.56 ; \mathrm{p}<.05\right)$ and openness to lifelong development $\left(\mathrm{R}^{2}=.36\right.$; $\mathrm{p}<05$ ). The mediator variable (lifelong learning) should have an impact on the dependent variable (personalprofessional competence) as shown in Figure 4.

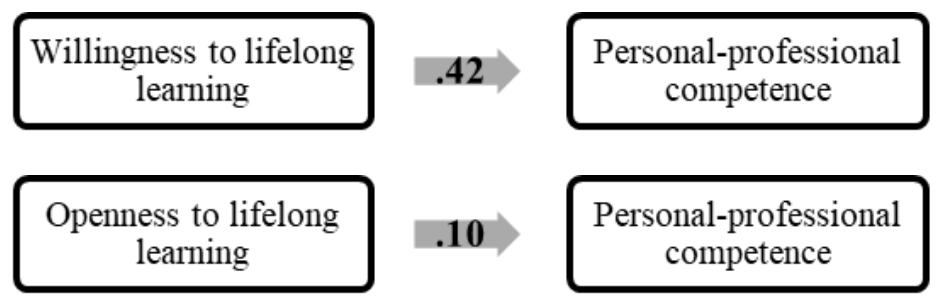

Figure 4. Third model of path analysis 
In the structural model analysis process, the sub-dimensions of the willingness to learn and openness to development of mediated variable lifelong learning and the dependent variable personal-professional competence were tested. The relationship between lifelong learning, willingness to learning and openness to development and personal-professional competence were found to be statistically significant. Willingness to lifelong learning has a positive and significant effect on personal-professional competence $\left(R^{2}=.42 ; p<.05\right)$; openness to lifelong learning does not significantly affect personal-professional competence $\left(\mathrm{R}^{2}=.10 ; \mathrm{p}>.05\right)$. Therefore, the path between lifelong learning openness and personal occupational competence was removed from the model. The final version of the model is shown in Figure 5. When the mediator variable (lifelong learning) and the independent variable (success motivation) are added to the model, the effect of the independent variable (success motivation) on the dependent variable (personal-professional competence) decreases; the effect of the mediator variable (lifelong learning) on the dependent variable (personalprofessional competence) should be significant [63].

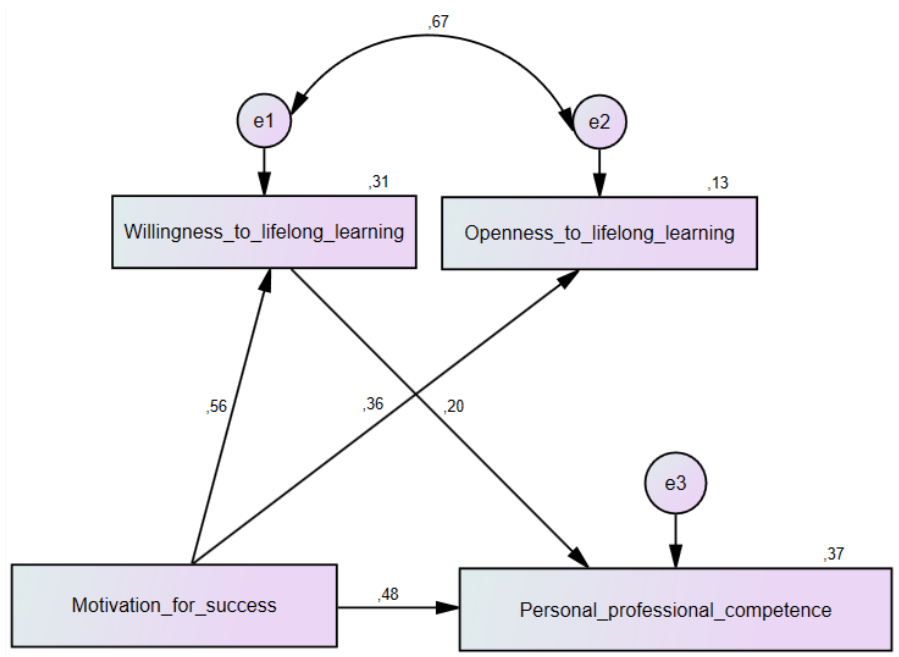

Figure 5. Fourth model of path analysis

At the beginning of the analysis, while the motivation of success and personal-professional competence affect $\mathrm{R}^{2}=.58$ at first, $\mathrm{R}^{2}=.48$ decreases through lifelong learning. In order to determine the measurement validity of the model, Chi-square and fit indexes were examined and two modifications were made in this process; covariance was added between error amounts because there was positive correlation between lifelong learning disposition and willingness to learn and openness to development. In the second stage, the openness to development sub-dimensions of lifelong learning did not significantly affect personalprofessional competence, so the arrow indicating the path coefficient was deleted and the analysis was repeated. As a result of the modification, Chi-square value $\left(X^{2}=2.49 ; \mathrm{df}=1 ; \mathrm{p}=0.11\right)$ calculated for the measurement model was significant. When the ratio of chi-square value to freedom degree is under 5 $\left(\mathrm{X}^{2} / \mathrm{df}=2.49\right)$, it shows that the results of the analysis are in good agreement. When the values of the goodness of fit indexes, of the measurement model are examined (RMSEA=.066, RMR=.006, NFI=.995, TLI=.983, GFI=.996, AGFI=.964 and CFI=.997), it was found that the model had good fit values. The regression path coefficients and variance values should be significant in addition to the fact that the fit indexes are within the adequate fit range when evaluating the mediation model. Therefore, the regression and variance values of the model are given in Table 3 and Table 4. As seen in Table 3 and Table 4, regression coefficients and variance values of mediation model variables were found to be significant $(\mathrm{p}<.05)$.

Table 3. Regression coefficients of the current model

\begin{tabular}{lclcccc}
\hline & & & Estimate & S.E. & C.R. & P \\
\hline Willingness to Lifelong Learning & $<--$ & Motivation for success & .797 & .064 & 12.399 & $* * *$ \\
Openness to lifelong development & $<-$ & Motivation for success & .522 & .073 & 7.143 & $* * *$ \\
Personal-professional competence & $<--$ & Motivation for success & .573 & .062 & 9.225 & $* * *$ \\
Personal-professional competence & $<--$ & Willingness to Lifelong Learning & .169 & .043 & 3.897 & $* * *$ \\
\hline
\end{tabular}


Table 4. Variance values for the current model

\begin{tabular}{lcccc}
\hline & Estimate & S.E. & C.R. & P \\
\hline Motivation for success & .229 & .018 & 13.096 & $* * *$ \\
Willingness to Lifelong Learning -e1 & .326 & .025 & 13.096 & $* * *$ \\
Openness to lifelong development -e1 & .420 & .032 & 13.096 & $* * *$ \\
Personal-professional competence -e3 & .210 & .016 & 13.096 & $* * *$ \\
\hline
\end{tabular}

\section{DISCUSSION}

In this study, the theoretical model developed for the mediating role of lifelong learning tendency in the relationship between success-oriented motivations and personal-professional competencies of university students was tried to be tested. According to the findings, success-oriented motivation significantly affects personal-professional competence. This result is consistent with the literature and supported by research on personal-professional competence with success-oriented motivation [34, 64, 65]. In addition, successoriented motivation is parallel to other variables in the research [66]. Educational researchers stated that motivation for success is predictor of academic success or personal-professional competence [67]. In addition, researchers stated that success motivation was significantly related to professional choice, life goals, focus of control and university satisfaction [68].

According to another result of the study, success-oriented motivation significantly affects lifelong learning. This result is consistent with previous studies [43,34]. When some studies that support this idea are examined, it is seen that teachers' lifelong learning tendencies are high and when the sub-dimensions of lifelong learning tendencies are examined, it is seen that motivation of success has the highest average [69]. In this context, university students are seen as learning individuals in line with their goals and objectives. There are various sources of motivation for learning, even if learning objectives change. In line with these sources of motivation, the individual is willing to learn. Within the scope of all these explanations, in order for students to be successful in lifelong learning, their motivation for success should be high and their needs should be shaped and oriented towards participating in learning experiences [70].

According to another finding of the study, lifelong learning tendency significantly affects personalprofessional competence. Within the scope of the studies supporting this idea, it is stated that lifelong learning tendency of university students is important in professional development [71]. Personal-professional competence requires personal-professional quality and personal-professional advancement within the scope of professional orientation. Personal-professional development can be defined as a career achieved through continuous efforts [72]. Continuous effort emphasizes the feature of lifelong learning.

When the results of the research were evaluated in integrity, it was seen that the relationship between success motivation and personal-professional competence and lifelong learning tendency acted as a partial mediator within this relationship. In this context, there are studies in the literature confirming the results [73]. It is seen that there is a positive relationship between achievement-oriented motivation, lifelong learning and personal-professional competence of university students. It is an indicator of the efforts to increase the motivation of success and lifelong learning tendencies in order to ensure the positive personal-professional competence of university students. Lifelong learning determines the new function of universities. It should not be forgotten that university students can stay up to date after graduation by continuing lifelong learning [74]. As a result, lifelong learning tendency has been accepted as one of the most valuable determinants of university students in terms of perception of personal-professional competence and motivation for success.

\section{CONCLUSION}

In the research, a model for the role of mediation in the relationship between the motivation of achievement and personal-professional competencies of university students' lifelong learning tendency was tested using the structural equation model. According to the model tested; success motivation and personal professional competences were also found to be statistically significant in the relationship between achievement motivation and lifelong learning inclination sub-dimensions of willingness to learn and openness to development. With the measurement analysis used in the structural equation model test process, it was determined that the motivation of success affects personal-professional competence through lifelong learning and is a partial tool of lifelong learning. 


\section{REFERENCES}

[1] TYÇÇ, Türkiye Yükseköğretim Yeterlilikler Çerçevesi: Temel Alan Yeterlilikleri Raporu (Turkey Higher Education Qualifications Framework), 2011. [Online]. Available: htpp://www.tyyc.sakarya.edu.tr/raporlar/14_ EGITIMBILIMLERI_13_01_2011.pdf

[2] A. Bandura, "Regulation of cognitive processes trough perceived self-efficacy," Devolopmental Psychology, vol. 25 , no. 5 , pp. $729-735,1989$.

[3] R. A. Swanson and E. F. Holdton, Faundations of human resources development. San Francisco: Berret Koehler Publishing, 2010.

[4] A. Z. Konan, "The HRD competencies as percevied by the human resource development professionals in bank in cote D'livore," (Doctoral Thesis), Indiana State University, Indiana, 2010.

[5] W. Westera, "Competences in education: A confusion of tongues," Journal of Curriculum Studies, vol. 33, no. 1, pp. 75-88, 2001.

[6] G. Nybo, "Personel management for dissolving jobs: Towards a competency-based approach?" International Journal of Human Resources Management, vol. 15, no. 3, pp. 549-564, 2004.

[7] S. Özdemir, "Competencies of human reseurces professionals and a research concerning perceptions of university students," (Master thesis), Çanakkale Onsekiz Mart University Social Sciences Institute, Çanakkale, 2014.

[8] R. E. Boyatsiz, The competent menager: A model for effective performance. New York: Wiley, 1982.

[9] M. Çetinkaya, "A research on managers' perceptions of managerial competence," Journal of Afyon Kocatepe University, vol. 11, no. 2, pp. 219-239, 2009.

[10] H. Kazu and D. Demiralp, "Personal-Professional Competencies Perception Scale for Teacher Candidates: Validity and Reliability Study," Educational Administration: Theory and Practice, vol. 23, no. 3, pp. 425-465, 2017.

[11] G. M. Marakas, M. Y. Yi and R. D. Johnson, "The multilevel and multifaceted character of computer self-efficacy: Toward clarification of the construct and an integrative framework for research," Information System Research, vol. 9, no. 2, pp.126-163, 1998.

[12] M. F. Pajares, "Self-efficacy beliefs in academic settings," Rewiew of Educational Research, vol. 66, no. 4, pp. 543-578, 1996.

[13] S. Ayhan, Lifelong learning from yesterday to today. Ankara: Pegem Publishing, 2006.

[14] N. Akkuş, "As a token of lifelong learning skills Pisa 2006 results of the evulation of Turkey," (Master thesis), Hacettepe University Social Sciences Institute. Ankara, 2008.

[15] M. Chien, "Power and knowledge in education: A critical exploration of lifelong learning," (Unpublished Doctoral thesis), Norther Ilinois University, 1996.

[16] E. Kivrak, "European Union and lifelong learning policies and evulation of employment," (Master thesis), Ankara University Institude of Educational Sciences. Ankara, 2007.

[17] OECD, "Building and Inovation Culture, in OECD science, Tecnology and Industry Outlook," 2012. [Online]. Available: htpp://www.oecd.org/sti/oecdsciencetechnologyandindustryoutlook.htm

[18] S. Elçi, Innovation:The key to development and competition. Ankara: Nova Publishing, 2006.

[19] E. Kurt, T. Cevher and N. Arslan, "Pre-service Turkish teachers' tendencies towards lifelong learning," Trakya Journal of Education, vol. 9, no. 1, pp. 152-160, 2019.

[20] K. Rubenson, "Adult education and training: the poor cousin. An analysis of Rewiev of National Polices for Education," MIMEO, Paris, 1997.

[21] H. Soran, B. Akkoyunlu, and Y. Kavak, "Life-long learning skills and training faculty members: A projectat Hacettepe University," H. U. Journal of Education, vol. 30, no. 30, pp. 201-210, 2006.

[22] Ministry of Education, Strategy of lifelong learning. Ankara: Ministry of Education, 2009.

[23] J. Chapmann, J. Gaff, R. Toomey and D. Aspin, "Policy of lifelong learning in Australia," International Journal of Lifelong Education, vol. 24, no. 2, pp. 397-414, 2015.

[24] G. Erdamar, "Lifelong learning," Ö. Demirel, (Edi), New orientation in education (5 ${ }^{\text {th }}$ edition), Ankara: Pegem Akademi, 2011

[25] E. Şenyuva, "Nursing student's view about distance education," International Online Journal of Educational Sciences, vol. 5, no. 2, pp. 409-420, 2013.

[26] Bologna Declaration, "Join declaration of the Evropean Ministers of Education, (19 June 1999)," 1999. [Online]. Available: http://www.ehea.info/Uploads/Declarations/BOLOGNA_DECLARATIONS1.pdf

[27] Z. Kaya, Psychological foundations of education: Introduction to teaching profession (Ö. Demirel and Z. Kaya, trans.). Ankara: Pegem Akademi, 2001.

[28] E. Eren, Management and organization. Istanbul: Beta Edition, 2001.

[29] D. H. Schunk, Learning theories: An educational perspective. Boston: Pearson Education, 2012.

[30] P. A. Story, J. W. Hart, M. F. Stasson and J. M. Mahoney, "Using two-factor theory of achievement motivation to examine performance-based and self-regulatory processes," Personality and Invidual Differencess, vol. 46, no. 4, pp. 391-395, 2009.

[31] G. Ülgün, Education psyclogy. Ankara: Alkım Publishing, 1997.

[32] İ. E. Başaran, Organizational behavior management. A.ய̈. Ankara: Faculty of Education Publications, 1982.

[33] M. Pozarnik, Learning and teaching psychology. Ljubljana: DZ, 2003.

[34] A. Ergin and H. Karataş, "Achievement-oriented motivation levels of university students," H. U. Journal of Education, vol. 33, no. 4, pp. 868-887, 2018.

[35] N. Senemoğlu, Development learning and teaching: From theory to practice. Ankara: Nobel Publishing, 2007.

[36] Ç. Semerci, "Development of success-oriented motivation scale," New World Since Academy, vol. 5, no. 4, pp. 2123-2133, 2010

The effect of motivation of success of university students on personal-professional competence ... (Halil Ekşi) 
[37] D. C. McClleland, "How motives, skills and values determine what people do?" American Psychologist, vol. 40, no. 7, pp. 812-825, 1985.

[38] E. L. Deci, Intrinsic motivation. New York: Plenum, 1975.

[39] D. C. McClleland, The achieving society. New Jersey: Van Nostrand Companylnc, 1961.

[40] H. Liao, A. C. Ferdenzi and M. Edlin, "Motivation, self-regulated learning efficacy and academic achievement among international and domestic students at an urban comunity cellege: Acomparison," Community College Enterprise, vol. 18, no. 2, pp. 9-38, 2012.

[41] S, Akbulut, A. Erol and S. Say, "The relationship between lifelong learning tendencies and occupational anxiety of the prospective teachers," Journal of Education and New Approaches, vol. 1, no. 1, pp. 1-11, 2018.

[42] M. Ayra and İ. Kösterelioğlu, "The relationship between teachers' lifelong learning tendencies and their perceptions of professional self-efficacy," NWSA-Education Sciences, vol. 10, no. 1, pp. 17-28, 2015.

[43] D. Karaman and U. Aydoğmuş, "Living length learning trends of university," Nevşehir Hacı Bektaş Veli University Journal of Social Sciences Institue, vol. 8, no. 1, pp. 23-44, 2018.

[44] S. Ekşioğlu, S. Tarhan and H. Ç. Gündüz, "The relationships between self efficacy expectations and personality traits with lifelong learning tendency," Kastamonu Journal of Educations, vol. 25, no. 5, pp. 1925-1940, 2017.

[45] Y. Duymuş and S. Sulak, "The effect of undergraduate education, gender and deparment on prospective teachers' lifelong learning," The Journal of Limitless Education and Research, vol. 3, no. 2, pp. 58-74, 2018.

[46] H. Güzel, "Lifelong learning tendency investigations of prospective," The Journal of International Education Science, vol. 4, no. 10, pp. 312-325, 2017.

[47] N. Tunca, S. Alkın Şahin and Ö. Aydın, "Life-long learning tendencies of pre-service teachers," Mersin University Journal of the Faculty of Education, vol. 11, no. 2, pp. 432-446, 2015.

[48] B. Turhan and B. Burgaz, "University students' views about the level of their personal and professional competences," Journal of Higher Education, vol. 4, no. 3, pp. 134-144, 2014.

[49] E, Yilmaz, "Relationships between educational philosphies favoured by prospective teachers and their achievement motivation," Bartin University Journal of Faculty Education, vol. 6, no. 3, pp. 1420-1429, 2017.

[50] A. Çalışkan, İ, Akkoç and Ö. Turunç, "The role of motivational behavior in creasing organizational performance: The mediating role of innovation and entrepreneurship," Suleyman Demirel University The Journal of Faculty of Economics and Administrative Sciences, vol. 16, no. 3, pp. 363-401, 2011.

[51] Ş. Büyüköztürk, E. K. Çakmak, Ö, E, Akgün, Ş. Karadeniz and F. Demirel, Scientific research methods. Ankara: Pegem Publishing, 2014.

[52] J. F. Hair, W. C. Black, B. J. Babin, R. E. Anderson and R. L. Tahtam, Multivariate data analysis. New Jersey: Pearson Education, 2006.

[53] Y. Karagöz, SPSS ve AMOS applied qualitative-quantitative-mixed scientific research methods and puplication ethics. Ankara: Nobel Publishing, 2017.

[54] T. Raykov and G. A. Marcoulides, A first course in structural equation modelling. Mahwah, NJ: Lawrence Erlbaum, 2006.

[55] Eroğlu, E., "Analysis of total quality management practices by Structural Equation Modeling," Istanbul University Journal of the School of Business, vol. 6, no. 1, pp. 7-25, 2005.

[56] R. Weston and Jr. P. A. Gore, "A brief guide to structural equation modelling," The Counseling Psychologist, vol. 34, no. 5, pp. 719-751, 2006.

[57] G. D. Erdoğan and Z. Arsal, "The development of lifelong learning trends scale," Sakarya University Journal of Education, vol. 6, no. 1, pp. 114-122, 2016.

[58] D. L. Hahs-Vaughn and R. G. Lomax, An indroduction to statistical concepts, ( $3^{\text {th }}$ edition). New York: Routledge, 2012.

[59] A. Ural and İ. Kılıç, Scientific research procces and data analysis with SPSS. Ankara: Detay, 2013.

[60] N. Bayram, Introduction to structural equation modeling AMOS applications. Istanbul: Ezgi Publishing, 2013.

[61] L. S. Meyers, G. Gamst and A. J. Guarino, Applied multivariate research: Design ans interpretation. London: Sage Puplications, 2006.

[62] Ö. F. Şimşek, Introduction to structural equation modeling: Basic principles and Lisrel applications. Ankara: Ekinoks, 2007.

[63] R. M. Baron and D. A. Kenny, "The moderator- mediator variable distinction in social psychological reseaerch: Conceptual, strategic and statistical considerations," Journal of Personality and Social Psychology, vol. 51, no. 6, pp. 1173- 1182, 1986.

[64] G. Eymur and Ö. Geban, "An investigation of the relationship between motivation and academic achievement of pre-service chemistry," Education and Science, vol. 36, no. 161, pp. 246-255, 2011.

[65] H. O. Küçükosmanoğlu, "A research on the determination of prospective music teachers' academic motivation levels (Konya example)," SED, vol. 3, no. 1, pp. 1-21, 2015.

[66] Ü. G. Durukan, D. Batman and N. Yiğit, "Study skills of teachers candidates," Inonu University Journal of Education, vol. 16, no. 1, pp. 63-80, 2015.

[67] H-A, Liao, A. C. Ferdenzi and M. Edlin, "Motivation, self-regulated learning efficacy, and academic achievement among international and domestic students at an urban community college: A comparison," Community College Enterprise, vol. 18, no. 2, pp. 9-38, 2012.

[68] E. D. D. Rosa and A. B. I. Bernardo, "Are two achievement goals better than one? Filipino students' achievement goals, deep learning strategies and affect," Learning and Individual Differences, vol. 27, no. 97, pp. 97-101, 2013. 
[69] M. Ayra, "The relationship of the lifelong learning tendencies of teachers with their self- confidence about their vocational proficiency," (Master thesis), Amasya University Social Sciences Institute, Amasya, 2015.

[70] Y. D. Coşkun, "Investigation of lifelong learning tendency of undergraduate students' in terms of some variables," (Doctoral thesis), Hacettepe University Institude of Social Departments Educational Sciences Department, Ankara, 2009.

[71] D. A. Kara and D. Kürüm, "The meaning of elementary teacher candidates on the concept of lifelong learning (Anadolu University Faculty Of Education Example)," National Educational Sciences Congress, Gaziosmanpaşa University Faculty of Education, Tokat-Turkey, 5-7 September, 2007.

[72] M. S. Schlager and J. Fusco, "Teacher professional development, technology and communiies of practice: Are we putting the cart before the horse?" The Information Society, vol. 19, no. 3, pp. 203-220, 2003.

[73] B. Akyol, "Teacher self-efficacy perceptions, learning oriented motivation, lifelong learning tendencies of candidate teachers: A modeling study," Eurasian Journal of Educational Research, vol. 16, no. 65, pp. 19-34, 2016.

[74] Y. D. Coşkun and M. Diker, "Lifelong learning tendencies of university students," H. U. Journal of Education, vol. 42, no. 42, pp. 108-120, 2012. 